\title{
Faktor Penyebab Penurunan Pelaporan Insiden Keselamatan Pasien Rumah Sakit
}

\section{Factors Influencing Low Hospital Patient Safety Incident Reporting}

\author{
Heru Iskandar ${ }^{1}$, Halimi Maksum², Nafisah ${ }^{1}$ \\ ${ }^{1}$ Program Studi Magister Manajemen Rumah Sakit Fakultas Kedokteran Universitas Brawijaya Malang \\ ${ }^{2}$ Rumah Sakit Daerah dr. Haryoto Lumajang
}

\begin{abstract}
ABSTRAK
Pelaporan insiden keselamatan pasien (IKP) adalah jantung dari mutu layanan sebagai dasar proses belajar dan revisi dari kebijakan serta perbaikan berkelanjutan. Studi pendahuluan menunjukkan angka IKP yang lebih rendah dari internasional dan cenderung menurun yang mengindikasikan "under reporting". Tujuan dari penelitian ini adalah untuk mengidentifikasi, menganalisis dan menentukan solusi faktor penyebab penurunan pelaporan IKP di RS X. Penelitian dilakukan dengan pendekatan kualitatif menggunakan Focus Group Discussion dengan peserta adalah 26 kepala ruang rawat inap/kepala instalasi RS X. IKP sebenarnya tinggi tetapi tidak dilaporkan, penyebabnya adalah takut disalahkan jika melapor sebab budaya patient safety yaitu no blaming masih belum tumbuh secara merata di seluruh RS, kurangnya pengetahuan tentang pelaporan IKP, keengganan melaporkan karena komitmen kurang dari pihak manajemen atau unit terkait, tidak ada reward dari RS jika melaporkan dan kurangnya keaktifan dari KKPRS. Perlu menumbuhkan budaya patient safety secara merata di RS dengan mengaktifkan kembali Patient Safety Champion (PSC). Dibutuhkan komitmen yang tinggi dari pihak direksi dan manajemen dalam program keselamatan pasien. Perlu monitoring dan evaluasi dari KPRS tentang pelaporan IKP dengan cara ronde keselamatan pasien dan visitasi secara periodik ke unit dan instalasi di rumah sakit.
\end{abstract}

Kata Kunci: Budaya keselamatan pasien, kemauan melaporkan, pelaporan insiden keselamatan pasien

\begin{abstract}
Patient safety incidents report is the core of service quality as a basis of learning process, policies revision and also continuous improvement. Preliminary study showed a lower rate compared to the international rate and tend to significantly decrease which indicates "under-reporting". The purpose of this study is to identify, analyze and determine the solution toward the underlying causes of low patient safety incidents report in X hospital. The study was conducted with a qualitative approach focused on group discussion performed with 26 participants of hospital head unit. The finding showed that the patient safety incident is high but under reported, the causes were fear of being blamed, for patient safety culture of 'no blaming' has not been cultivated evenly throughout the hospital, the lack of knowledge about patient safety incident report, reluctant in reporting related to less commitment from management or related units, no reward from the hospital for the reporting and lack of hospital safety committee activity. It is needed to encourage a culture of patient safety in hospital evenly by reactivating Patient Safety Champion (PSC), to have a strong commitment from the directors and management to the patient safety program, and lastly, to present monitoring and evaluation from the committee about patient safety reporting by continuous monitoring and periodic visitation to the unit $n$ the hospital.
\end{abstract}

Keywords: Patient safety culture, patient safety incident reporting, reporting willingness

Jurnal Kedokteran Brawijaya, Vol. 28, Suplemen No. 1, 2014: Heru Iskandar. Program Studi Magister Manajemen Rumah Sakit Fakultas Kedokteran Universitas Brawijaya Malang, Jl. Veteran Malang 65142 Tel. (0341) 568989 Email: heruiskandarhukum@gmail.com 


\section{PENDAHULUAN}

Keselamatan pasien menurut WHO adalah tidak adanya bahaya yang mengancam kepada pasien selama proses pelayanan kesehatan (1). Keselamatan pasien identik dengan kualitas pelayanan, karena semakin baik kualitas layanan maka keselamatan pasien akan semakin baik. Standar akreditasi rumah sakit versi 2012 mengacu pada patient centered, patient safety, good governance, dan MDGs, dengan $80 \%$ muatan standar adalah patient safety (2). Salah satu fakta keselamatan pasien yang dirilis oleh WHO bahwa di negara berkembang satu dari sepuluh pasien mengalami cedera ketika mendapatkan layanan kesehatan. WHO melaporkan dari berbagai negara kejadian tidak diharapkan (KTD) pasien rawat inap sebesar 3-16\%. Di New Zealand KTD dilaporkan berkisar 12,9\% dari angka rawat inap (3), di Inggris KTD dilaporkan berkisar 10,8\% (4), di Kanada dilaporkan berkisar 7,5\% (5). Joint Commission International (JCl) juga melaporkan KTD berkisar $10 \%$ dan di United Kingdom, dan 16,6\% di Australia (6).

Setiap pelayanan selalu mempunyai potensi risiko dengan besar risiko yang berbeda. Perbedaan ini tergantung pada bagaimana masing-masing pelayanan merancang sistem sedemikian rupa sehingga lebih menjamin keselamatan para pelanggannya (7). Salah satu strategi dalam merancang sistem keselamatan pasien adalah bagaimana mengenali kesalahan sehingga dapat dilihat dan segera dapat diambil tindakan guna memperbaiki efek yang terjadi. Upaya untuk mengenali dan melaporkan kesalahan ini dilakukan melalui sistem pelaporan. Kegagalan aktif (petugas yang melakukan kesalahan) yang berkombinasi dengan kondisi laten akan menyebabkan terjadinya suatu kesalahan berupa kejadian nyaris cedera (KNC), KTD, atau bahkan kejadian yang menyebabkan kematian atau cedera serius (sentinel). Berhenti sampai tahap melaporkan saja tentu tidak akan meningkatkan mutu dan keselamatan pasien, yang lebih penting adalah bagaimana melakukan suatu pembelajaran dari kesalahan tersebut sehingga dapat diambil solusi agar kejadian yang sama tidak terulang kembali.

RS X adalah rumah sakit milik Pemerintah di Propinsi Jawa Timur dengan status Badan Layanan Umum penuh, telah terakreditasi 16 pelayanan sekaligus terakreditasi sebagai rumah sakit pendidikan pada tahun 2011. Selama tahun 2012 tercatat data kunjungan rawat jalan sebesar 245.323 pasien dengan rata-rata 817 pasien per hari, BOR rawat inap 67,23\%, ALOS 4,52, TOI 2,51, BTO 52,11, NDR 40,28\%, GDR 90,07\%, tindakan operasi 5.421 kali operasi $(8,9)$. Pelaporan insiden keselamatan pasien yang masuk ke KKPRS mulai tahun 2011-2013 adalah tahun 2011 sebanyak 19 laporan, tahun 2012 sebanak 41 laporan (0,22\% dari admisi), tahun 2013 sebanyak 3 laporan. Data tersebut menunjukkan rendahnya persentase laporan KTD RS X yang hanya $<1 \%$ bila dibandingkan dengan teori yaitu berkisar $10 \%$

Pelaporan insiden keselamatan pasien adalah jantung dari mutu layanan, yang merupakan bagian penting dalam proses belajar dan pembenahan ke dalam, peremajaan, revisi dari kebijakan, termasuk standar prosedur operasional (SPO) dan panduan yang ada. Rendahnya pelaporan insiden mendorong pentingna kajian faktor penyebab rendahnya pelaporan insiden keselamata pasien. Tujuan dari penelitian ini adalah untuk mengidentifikasi, menganalisis dan menentukan solusi faktor penyebab penurunan pelaporan insiden keselamatan pasien RS $\mathrm{X}$. Hasil penelitian diharapkan dapat memberikan kontribusi untuk membangun budaya kesselamatan pasien yang akan meningkatkan pelaporan inisiden dan potensial insiden sebagai dasar dalam pembenahan sistem manajemen keselamatan pasien.

\section{METODE}

Metode yang digunakan adalah menggunakan Focused Group Discussion (FGD) dengan peserta adalah mereka yang terlibat langsung sesuai alur pelaporan di RS $X$ tersebut yaitu kepala ruang rawat inap/kepala instalasi sebanyak 26 orang. Diskusi dilakukan dalam dua tahap. Pada tahap pertama peserta dibagi menjadi 3 kelompok dan masing-masing kelompok dipandu oleh seorang moderator. Moderator bertugas memimpin diskusi secara terarah dengan fokus diskusi faktor-faktor penyebab rendahnya pelaporan IKP di RS X. Hasil diskusi masingmasing kelompok didiskusikan kembali dengan seluruh peserta pada tahap kedua. Diambil prioritas masalah dengan metode (Urgency, Seriousness, Growth) USG dengan nilai skala 1-5. Masalah yang terpilih selanjutnya didiskusikan alternatif pemecahan masalah dan diambil prioritas pemecahan masalah dengan metode tapisan Mc. Namara.

\section{HASIL}

Peserta mengidentifikasi penyebab rendahnya pelaporan Insiden Keselamatan Pasien (IKP) di RS X. Dari diskusi didapatkan 7 akar masalah pokok, yaitu 1) takut disalahkan oleh karena budaya patient safety belum menyeluruh ke seluruh rumah sakit, 2) komitmen kurang dari pihak manajemen atau unit terkait, 3) tidak ada reward dari RS jika melaporkan, 4) tidak tahu batasan mana atau apa yang dilaporkan, 5) sosialisasi IKP kurang maksimal, 6) belum ikut pelatihan, 7) sosialisasi Komisi Keselamatan Pasien Rumah Sakit (KKPRS) kurang aktif.

\section{Takut Disalahkan}

Alasan takut disalahkan atau blaming terdapat pada ketiga kelompok FGD. Mereka beranggapan walaupun sudah keluar kebijakan yang dituangkan dalam bukti surat keputusan direktur tentang adanya perlindungan hukum kepada pelapor IKP tetapi hal ini tidak menghilangkan adanya blaming ataupun disalahkan oleh pihak lain, misalnya oleh unit lain yang mendengar masalah tersebut. $\mathrm{Hal}$ ini disebabkan budaya patient safety belum menjadi budaya yang membumi di seluruh rumah sakit. Peserta mengatakan "Memang kita tahu dan mengerti tentang pentingnya pelaporan IKP, tetapi apakah yang lain atau bagian yang lain juga mengerti, ujung-ujungnya kalau kita melapor bukan pujian atau penghargaan yang kita dapat tetapi cemoohan, cap jelek kepada kita oleh bagian lain, sebab mereka masih berpikir bahwa masalah yang kita laporkan adalah disebabkan kesalahan kita secara pribadi". Penanganan kesalahan masih dilihat pelakunya atau orang per orang bukan dilihat dari kesalahan sistem.

\section{Kurangnya Komitmen}

Kurangnya komitmen dari pihak terkait antara lain KPRS, manajemen rumah sakit, instalasi pemeliharaan dan sarana (IPS) merupakan salah satu penyebab penurunan pelaporan IKP. Pelapor menjadi malas dan putus asa karena ketika sudah dilaporkan tidak ada atau kurang 
cepat ditindaklanjuti. Peserta mengatakan "Percuma melapor, sebab baik dari manajemen maupun KPRS tidak ada tindak lanjut, brankart rusak yang sudah sampai menyebabkan pasien jatuh $2 x$ saja, harus menunggu lama untuk perbaikan dan penggantian, alasannya anggaran yang ada belum tersedia atau harus menunggu anggaran berikutnya". Di bagian IPS pun adanya kerusakan alat yang telah dilaporkan berulang kali, walaupun sudah dibenahi tetapi tetap sering rusak, tidak ada tindak lanjut usulan pengadaan dari pihak IPS.

\section{Reward.}

Tidak adanya reward juga menjadi salah satu penyebab penurunan pelaporan IKP. Peserta FGD beralasan dengan adanya reward, maka mereka akan lebih bersemangat. Reward dalam hal ini dapat berupa jasa pelayanan yang diberikan langsung ke pelapor ataupun ke unit pelapor, bingkisan atau hadiah pada unit yang sering melapor setiap hari raya dan kemudahan pemenuhan sarana dan prasarana bagi unit yang sering melapor. Peserta mengatakan "Jika ada imbalan, misalnya bagi unit atau ruangan yang sering melaporkan IKP maka akan diperlancar pemenuhan sarana dan prasarana di unit tersebut, pasti semua unit akan berlomba-lomba melaporkan jika terjadi IKP".

\section{Kurangnya Pengetahuan tentang Pelaporan IKP}

Kurangnya pengetahuan tentang pelaporan IKP juga menjadi sebab penurunan pelaporan IKP. Kurangnya pengetahuan yang dimaksud adalah tidak tahu kalau IKP wajib dilaporkan, siapa yang harus melaporkan, apa yang harus dilaporkan, kemana dan kepada siapa mau melapor, bagaimana cara melapor, dan tidak tahu bentuk formulir laporan IKP, cara mendapatkan formulir dan cara pengisiannya. Dari seluruh peserta terdapat 5 orang peserta yang belum pernah mengikuti pelatihan pelaporan IKP, sebab mereka baru saja diangkat sebagai kepala ruang atau kepala instalasi. Rata-rata mereka menggantikan kepala ruang/kepala instalasi yang telah habis masa tugasnya atau pensiun. Kepala ruang/kepala instalasi yang dilatih rata-rata tidak meneruskan materi pelatihan KPRS kepada stafnya, sehingga staf tidak memahami tentang pelaporan IKP. Sejak tahun 2010 pelatihan pelaporan IKP sudah 3 kali dilaksanakan.

Dari hasil diskusi didapatkan bahwa formulir laporan setelah didapat pada saat pelatihan tidak digandakan dan tidak diletakkan di tempat yang terbuka sehingga mudah diambil. Formulir disimpan oleh kepala ruang sehingga staf atau karyawan yang akan melaporkan IKP kesulitan untuk mendapatkan formulir tersebut. Kepala ruang sebagai patient safety champion tidak secara intensif atau terus menerus mengingatkan masalah pelaporan IKP terhadap staf atau bawahannya. Posisi sekretariat KPRS tidak jelas, karena sejak tahun 2011 ruang sekretariat KPRS dihilangkan digunakan untuk keperluan lain, sehingga beberapa kepala ruang tidak tahu harus melapor atau menaruh laporan dimana yang diperburuk dengan kurangnya keaktifan KKPRS. Setelah diadakan pelatihan kurang adanya monitor dan evaluasi dari KKPRS dalam hal pelaporan IKP. Peserta meminta KKPRS dapat memonitor dan evaluasi pelaporan IKP tiap bulan dengan berkunjung ke masing-masing unit atau ruangan.

\section{Akar Masalah dan Solusi}

Dengan metode USG (Urgency, Seriousness, Growth) menggunakan skor 1-5 didapatkan tiga prioritas masalah yaitu takut disalahkan oleh karena budaya patient safety belum menyeluruh ke seluruh rumah sakit, komitmen yang kurang dari pihak manajemen atau unit terkait, dan tidak ada imbalan dari RS jika melaporkan (Tabel 1).

Tabel 1. Penetapan prioritas masalah dengan metode USG

\begin{tabular}{llcccc}
\hline No. & \multicolumn{1}{c}{ Akar Masalah } & U & S & G & Skor Total \\
\hline 1. & $\begin{array}{l}\text { Takut disalahkan oleh karena } \\
\text { budaya patient safety belum } \\
\text { menyeluruh ke seluruh RS }\end{array}$ & 91 & 92 & 82 & 265 \\
& & & & \\
2. & $\begin{array}{l}\text { Komitmen kurang dari } \\
\text { pihak/manajemen terkait }\end{array}$ & 92 & 94 & 87 & 273 \\
3. & Tidak ada reward & 56 & 89 & 85 & 230 \\
4. & Tidak tahu batasan mana atau apa & 72 & 76 & 87 & 235 \\
& yang dilaporkan & & & & \\
5. & Sosialisasi IKP kurang Maksimal & 72 & 78 & 73 & 223 \\
6. & Belum ikut pelatihan & 62 & 62 & 74 & 198 \\
7. & KPRS kurang aktif & 65 & 68 & 60 & 193 \\
\hline
\end{tabular}

Dari 3 akar masalah dicari alternatif solusi dengan menggunakan tapisan Mc. Namara. Hasil identifikasi alternatif solusi disajikan pada Tabel 2 .

Tabel 2. Identifikasi alternatif solusi dan penetapan solusi

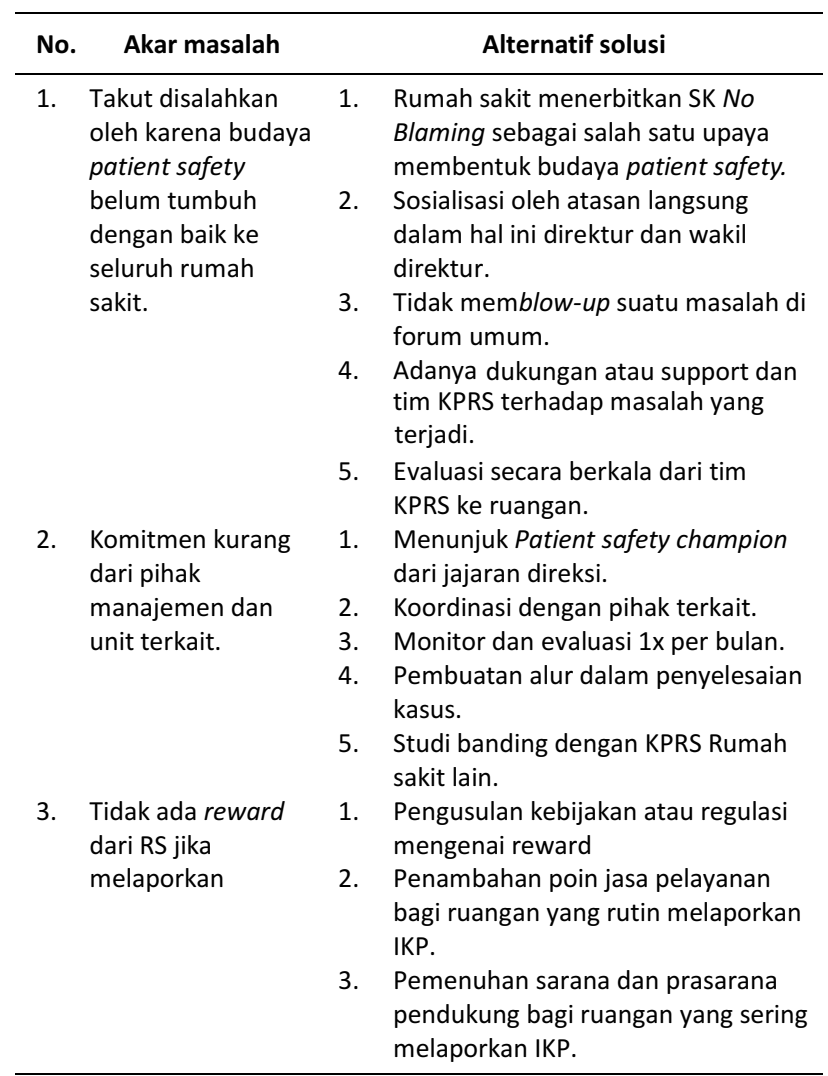

\section{DISKUSI}

Budaya Keselamatan Pasien

Budaya keselamatan pasien dibangun atas dasar kepercayaan. Kepercayaan ini akan mendorong staf untuk melaporkan kesalahan, kejadian tidak diharapkan, 
kejadian nyaris cedera, dan mengenali kegiatan, perlakuan atau budaya yang dapat membahayakan pasien. Semua yang tersebut di atas akan meningkatkan keselamatan pasien (10). Dari hasil FGD didapatkan kepala ruang atau unit di RS $\mathrm{X}$ masih takut melaporkan IKP. Ketakutan ini disebabkan adanya budaya blaming atau disalahkan, walaupun mereka tahu bahwa budaya blaming merupakan hal yang tidak benar dalam budaya keselamatan pasien. Staf beranggapan bahwa budaya keselamatan pasien masih belum merata di seluruh rumah sakit, hanya sebagian kecil saja yang mengerti, sehingga apabila ada pelaporan pasti akan tetap disalahkan atau dicemooh oleh orang atau unit yang lainnya. Hal ini sesuai dengan Manhajan, yaitu faktor penghambat pelaporan IKP salah satunya adalah ketakutan akan adanya hukuman dan rendahnya budaya keselamatan (11). Menurut Sora et al dalam Exploring relationships between patient safety culture and patients' assessments of hospital care, bahwa rumah sakit dimana seluruh staf, pihak pimpinan dan manajemen yang mengerti dan mempunyai persepsi positif terhadap budaya keselamatan pasien, pasien menilai pelayanan mereka lebih baik. Budaya keselamatan pasien yang harus didukung antara lain komunikasi yang terbuka, adanya feedback dan komunikasi jika ada kesalahan, tidak ada hukuman atau bahkan pemberian hadiah bagi mereka yang melaporkan, budaya pihak manajemen yang selalu mendukung program keselamatan pasien, dan pembelajaran organisasi yang terus menerus (12). Dalam hal ini peran rumah sakit adalah membangun kesadaran akan nilai keselamatan pasien, seperti yang tertera pada langkah pertama menuju keselamatan pasien.

Budaya yang sangat kental dan perlu dihilangkan saat ini adalah budaya menyalahkan, menghukum dan mempermalukan orang lain yang mempunyai kesalahan masih merupakan hambatan untuk terciptanya keselamatan pasien. Hal ini berkaitan dengan openness atau keterbukaan melaporkan semua kesalahan yang terjadi. Banyak tenaga kesehatan yang takut akan melaporkan kesalahan sebab takut akan hukuman, misalnya tiga kali melaksanakan kesalahan maka staf harus keluar, sehingga tidak ada keterbukaan. Suatu kesalahan hendaknya dilihat dari segi sistem, sehingga penanganannya adalah kembali ke sistem dengan cara perbaikan sistem dengan harapan kejadian serupa tidak terulang lagi (13). Dari hasil FGD didapatkan bahwa walaupun sudah ada SK direktur tentang adanya perlindungan hukum bagi yang melapor tetap hal itu tidak menghilangkan blaming. Perlindungan hukum adalah suatu perlindungan yang diberikan kepada subjek hukum sesuai dengan aturan hukum, baik itu yang bersifat preventif (pencegahan) maupun dalam bentuk yang bersifat represif (pemaksaan), baik yang secara tertulis maupun tidak tertulis dalam rangka menegakkan peraturan hukum, sehinga pada hakikatnya seluruh rakyat Indonesia berhak memperoleh perlindungan hukum dari negara. Artinya perlindungan hukum oleh rumah sakit lebih condong ke arah bantuan hukum, sehingga dalam hal budaya blaming perlu SK yang memperkuat untuk menghilangkan budaya tersebut.

Komitmen Direksi dan Manajemen, serta Peran Patient Safety Champion

Keselamatan pasien merupakan isu kepemimpinan dan manajemen yang tergantung kepada faktor sistemik, tetapi dalam praktek keselamatan pasien hanya melibatkan tenaga medis dan pasien. Secara garis besar penerapan keselamatan pasien dipengaruhi oleh pemerintah, manajemen rumah sakit, tenaga medis, pasien, dan budaya keselamatan itu sendiri (13). Keselamatan pasien identik dengan kualitas pelayanan, semakin baik kualitas layanan maka keselamatan pasien juga akan semakin baik. Dalam bisnis banyak pandangan buruk terhadap upaya peningkatan kualitas. Pandangan tersebut antara lain adalah anggapan peningkatan kualitas hanyalah suatu proses yang tidak efisien, pencegahan yang kurang perlu, atau terlalu berlebihan dalam hal penanganan suatu masalah sehingga menyebabkan pengeluaran biaya yang merugikan perusahaan dalam hal ini rumah sakit, dan fakta di Amerika Serikat sebanyak $40 \%$ dari pengeluaran biaya adalah pengeluaran yang sia-sia, sehingga banyak sekali hambatan dan tantangan yang berasal dari pihak manajemen (2).

Dalam koridor bisnis pelayanan terhadap pasien harus dipilah-pilah, antara pelayanan yang menggambarkan pelayanan dibawah standar, tidak efisien, defektif atau pelayanan yang berlebihan, sehingga pihak manajemen dapat menjalankan program peningkatan kualitas tanpa merugikan rumah sakit, dan tujuan peningkatan kualitas yaitu keselamatan pasien dapat tercapai (2). Menurut Levey et al dalam Hospital Leadership and Quality Improvement: Rhetoric Versus Reality menyebutkan bahwa dalam hal retorika pihak manajemen berpendapat bahwa peningkatan kualitas harus menjadi prioritas diseluruh sektor layanan kesehatan, tetapi dalam kenyataannya mereka takut bahwa peningkatan kualitas hanyalah akan memberikan pengeluaran biaya yang tidak perlu (14). Mereka resisten terhadap perubahan dan masih beranggapan bahwa pelayanan yang saat ini dilakukan adalah sudah aman dan tidak perlu adanya perubahan atau belum perlu peningkatan kualitas layanan. Ketiadaan atau kurangnya dana sering menjadi penghalang, misalnya dana untuk pelatihan medis ataupun pengenalan teknologi baru. Perlu ditekankan bahwa bisnis yang berorientasi pada keselamatan pasien adalah investasi di masa datang. Rumah sakit akan memiliki ciri khas tersendiri dan mendongkrak reputasi rumah sakit, dan akan meningkatkan pendapatan rumah sakit dalam jangka waktu lama, sehingga sangat mungkin pihak manajemen untuk melaksanakan program keselamatan pasien (2). Hal ini sesuai dengan langkah kedua dari tujuh langkah menuju keselamatan pasien, yaitu memimpin dan mendukung staf, membangun komitmen dan fokus yang kuat dan jelas tentang keselamatan pasien rumah sakit. Pada langkah ini rumah sakit harus memastikan ada anggota direksi yang bertanggung jawab atas keselamatan pasien dan memprioritaskan keselamatan pasien dalam agenda rapat direksi maupun rapat-rapat manajemen rumah sakit.

Untuk mendukung program tersebut perlu adanya sistem yang bisa memecahkan masalah. Upaya tersebut dapat berupa pertemuan rutin yaitu ronde keselamatan pasien minimal tiap satu bulan sekali yang terdiri dari direksi, manajemen rumah sakit, kepala ruang atau instalasi dan KPRS. Ronde keselamatan pasien dapat berfungsi sebagai 1) forum tanya jawab dan feed back atau pemecahan masalah dari pelaporan IKP, 2) merupakan bentuk komitmen dari pihak direksi dan manajemen rumah sakit dalam hal keselamatan pasien rumah sakit, 3) forum pelaporan IKP kepala ruang dan kepala instalasi tiap bulan kepada KPRS, dilanjutkan visitasi ke masing-masing ruang atau instalasi untuk melakukan monitor dan evaluasi 
program keselamatan pasien.

Hambatan lain dari sisi pemimpin dan manajemen adalah kurangnya SDM yang berkompeten dalam perencanaan, pelaksanaan, evaluasi dan kontrol dari program keselamatan pasien. Peran pemegang program ini penting sebab bertanggungjawab dalam hal upaya peningkatan kualitas layanan secara terus menerus tiap harinya. Oleh karena itu pemimpin yang diharapkan agar program keselamatan ini berjalan adalah pemimpin yang berwawasan luas dan sangat perhatian terhadap keselamatan pasien (13). Dengan patient safety champion di tiap-tiap unit kerja diharapkan kepala poli atau kepala ruang menjadi agen perubahan dan sosialisasi budaya keselamatan pasien. Permasalahan yang ada saat ini menunjukkan perlunya evaluasi dan peremajaan kembali patient safety champion di tiap unit atau bagian. Apabila fungsi dan kerja patient safety champion berjalan dengan baik, maka budaya keselamatan pasien akan lebih mengakar ke seluruh karyawan rumah sakit, sehingga terjadi transfer ilmu dan pengetahuan tentang keselamatan pasien dari kepala ruang kepada bawahannya. Dampak minimal yang diharapkan pengetahuan tentang pelaporan IKP dapat ditingkatkan dan ketidaktahuan akan hal apa yang harus dilaporkan dan bagaimana cara melaporkan IKP dapat dihindari.

Dari hasil FGD didapatkan bahwa peserta kesulitan dalam pengumpulan pelaporan disebabkan tidak adanya sekretariat KPRS. Dilihat dari pentingnya program keselamatan pasien dalam akreditasi rumah sakit yang akan datang maka perlu kiranya dukungan dari pihak manajemen rumah sakit untuk pengadaan sekretariat KPRS demi lancarnya tugas KPRS kedepan.

\section{Imbalan terhadap Pelaporan Insiden Keselamatan Pasien}

Menurut Rijanto faktor-faktor yang mempengaruhi kepuasan kerja tenaga medis adalah imbalan, promosi dan hubungan dengan teman sekerja. Semakin puas tenaga kerja maka kualitas pelayanan akan semakin baik. Pada dasarnya seseorang yang bekerja mengharapkan imbalan yang sesuai dengan jenis pekerjaannya. Karena adanya insentif yang sesuai dengan pekerjaannya, maka akan timbul pula rasa gairah kerja yang semakin baik. Imbalan adalah hal-hal yang mendorong tenaga kerja untuk bekerja lebih giat. Imbalan merupakan pengakuan dan penghargaan manajemen terhadap karyawan. Imbalan yang bisa meningkatkan kepuasan kerja adalah imbalan ekstrinsik dan intrinsik. Imbalan ekstrinsik berasal dari pekerjaan meliputi uang, status, promosi, rasa hormat, dan perhatian. Imbalan intrinsik merupakan bagian dari pekerjaan itu sendiri meliputi cara penyelesaian, prestasi, dan otonomi bagian (15). Dari hasil FGD semua kepala ruang menginginkan imbalan dari pelaporan IKP untuk mendongkrak kenaikan pelaporan IKP yang berujung pada keselamatan pasien. Imbalan ini dapat berupa hadiah, jasa pelayanan, penghargaan, atau pemenuhan sarana dan prasarana bagi unit atau ruang

\section{DAFTAR PUSTAKA}

1. World Health Organization. Patient Safety, About Us. (Online). http://www.who.int/patientsafety/about/ en/index.html [diakses tanggal 29 Mei 2013].

2. Swensen SJ, Dilling JA, Mc Carty PM, Bolton JW, and Harper CMJ. The Business Case for Health-Care yang sering melaporkan IKP.

Pelaporan IKP sangat penting untuk meningkatkan keselamatan pasien. Dengan adanya pelaporan IKP maka sistem pelayanan dapat diperbaiki sehingga tidak terulang lagi kesalahan yang sama. Faktor penyebab penurunan pelaporan IKP di RS X adalah adanya ketakutan disalahkan (blaming) jika melaporkan IKP, kurangnya komitmen dari direksi dan manajemen untuk mendukung program keselamatan pasien dan belum adanya imbalan jika melaporkan IKP. Adanya ketakutan disalahkan disebabkan oleh karena belum meratanya budaya keselamatan pasien di seluruh karyawan rumah sakit. Penanganan kesalahan masih berorientasi pada orang sehingga mereka yang melakukan kesalahan akan dianggap salah, dan bukan kesalahan pada sistem. Kurangnya komitmen dari direksi dan manajemen dilihat dari kurangnya feed back dari pihak manajemen atas permasalahan-permasalahan IKP yang dilaporkan. Imbalan baik berupa penghargaan, piagam, hadiah ataupun pemenuhan sarana dan prasarana di unit yang sering melaporkan IKP dapat sebagai alat untuk mendorong karyawan untuk melaporkan IKP. Beberapa hal yang dapat direkomendasikan sebagai solusi yaitu mempertegas komitmen pihak manajemen rumah sakit dalam hal keselamatan pasien dengan membentuk tim yang terdiri dari direksi, manajemen dan KPRS untuk melakukan evaluasi secara berkala keselamatan pasien ke ruangan-ruangan. Rumah sakit juga dapat melakukan ronde keselamatan pasien oleh jajaran direksi didampingi KPRS dan manajemen rumah sakit serta mempertegas tidak adanya blaming dengan dikeluarkannya kebijakan tentang no blaming pada pelaporan IKP. Rumah sakit perlu melakukan evaluasi, penguatan dan peremajaan kembali patient safety champion sebagai penggerak budaya keselamatan pasien. Dukungan rumah sakit terhadap budaya keselamatan pasien juga dapat berupa pemberian imbalan dalam bentuk penghargaan atau hadiah kepada unit yang sering melaporkan IKP; pengadaan ruang KKPRS untuk memperlancar jalannya program keselamatan pasien. Hal tersebut perlu ditunjang dengan meningkatkan monitoring dan evaluasi oleh KPRS ke masing-masing unit tiap bulan.

Banyak sekali hambatan yang akan dilalui oleh program keselamatan pasien untuk berjalan dengan lancar antara lain dari sisi pemilik rumah sakit, pihak direktur dan manajemen, tenaga kesehatan dan pasien. Perubahan budaya ke arah budaya keselamatan pasien merupakan faktor utama keberhasilan program keselamatan pasien. Faktor yang menjadi kunci adalah komitmen dari semua stake holder diatas untuk menjalankan program keselamatan pasien. Perlu transisi konseptual bahwa peningkatan kualitas layanan dan keselamatan pasien berkorelasi positif terhadap pelayanan rumah sakit, kepuasan pasien dan peningkatan pendapatan rumah sakit. Semua komponen rumah sakit harus berusaha merubah budaya sesuai dengan prinsip-prinsip keselamatan pasien serta diimplementasikan dalam kegiatan pelayanan kesehatan sehari-hari.
Quality Improvement. Journal of Patient Safety. 2013; 9(1): 44-52.

3. Davis P, Lay-Yee R, Briant R, et al. Adverse Events in New Zealand Public Hospitals: Principal Findings from a National Survey. Wellington, New Zealand: The Ministry of Health; 2001. 
4. Vincent C, Neale G, and Woloshynowych M. Adverse Events in British Hospitals: Preliminary Retrospective Record Review. British Medical Journal. 2001; 322(7285): 517-519.

5. Baker GR, Norton PG, Flintoft V, et al. The Canadian Adverse Events Study: The Incidence of Adverse Events Among Hospital Patients in Canada. Canadian Medical Association Journal. 2004; 170(11): 16781686.

6. World Health Organization. 10 Facts on Patient Safety. (Online). http://www.who.int/features/factfiles/ patient_safety/patient_safety_facts/en/index1.html [diakses tanggal 29 Mei 2013].

7. Tim RS RK Charitas Palembang. Menuju Pelayanan Kesehatan yang Aman, Kapita Selekta Keselamatan Pasien di Rumah Sakit. Yogyakarta: Kanisius; 2007.

8. RS X. Laporan tahunan RSD X Jawa Timur tahun 2012. Jawa Timur: RSX; 2013.

9. RSX. Profil RSD X Jawa Timur tahun 2012. Jawa Timur: RSX; 2013.

10. Joint Commission Center for Transforming Healthcare. Creating a Safety Culture. Joint
Commission Center for Transforming Healthcare. (Online.) http://www.centerfortransforming healthcare.org/multimedia/creating-a-safetyculture/ [diakses tanggal 29 Mei 2013].

11. Mahajan RP. Critical Incident Reporting and Learning. British Journal of Anaesthesia. 2010; 105(1): 69-75.

12. Sorra J, Khanna K, Dyer N, Mardon R, and Famolaro T. Exploring Relationships between Patient Safety Culture and Patients' Assessments of Hospital Care. Journal of Patient Safety. 2012; 8(3): 131-139.

13. Akins RB and Cole BR. Barriers to Implementation of Patient Safety Systems in Healthcare Institutions: Leadership and Policy Implications. Journal of Patient Safety. 2005;1(1):9-16.

14. Levey S, Vaughn T, Koepke M, Moore D, Lehrman W, and Sinha S. Hospital Leadership and Quality Improvement: Rhetoric Versus Reality. Journal of Patient Safety. 2007; 3(1): 9-15.

15. Rijanto NE. Analisis Kepuasan Kerja Tenaga Medis di Unit Rawat Jalan RSI Darul Istiqomah Kaliwungu Kendal Tahun 2009. Semarang: Universitas Diponegoro; 2011. 